\title{
Coexistence of innovation and standardization: evidence from the lean environment of business process outsourcing
}

\author{
Ewelina Zarzycka ${ }^{1}$ (D) Justyna Dobroszek ${ }^{1} \cdot$ Lauri Lepistö $^{2}$. \\ Sinikka Moilanen ${ }^{3}$
}

Published online: 20 May 2019

(c) The Author(s) 2019

\begin{abstract}
It has been argued that companies face the challenge of being innovative while at the same time having to standardize and control organizational processes. While management control research has mostly focused on how control supports innovation, the present study aims to improve our understanding of how controls can support the co-existence of process and management innovations with standardization. The paper adopts a single-case study method and analyses the use of a management control system in the context of a business process outsourcing company which faces the simultaneous need for process and management innovation and standardization. The study examines the relationships between different levers of control and their nature to explain how levers of control can create consistent and countervailing reinforcement that supports the co-existence of innovation and standardization. Moreover, we provide an insight into how certain controls, specifically diagnostic and interactive lean controls, combine the levers of control, so creating countervailing reinforcement. We show that the identified reinforcement enables the coexistence of different innovations and standardization at various organizational levels. Thus, the current study contributes to the stream of research on how management controls work collectively, acknowledging their impact on innovation and the concurrent need for standardization.
\end{abstract}

Keywords Outsourcing · Levers of control · Process innovation · Management innovation - Standardization $\cdot$ Lean

JEL Classification M41

Ewelina Zarzycka

ezarzycka@uni.lodz.pl

1 Department of Accounting, Faculty of Management, University of Lodz, Matejki 22/26, 90-237 Lodz, Poland

2 Turku School of Economics, Pori Unit, University of Turku, P.O. Box 170, 28101 Pori, Finland

3 Oulu Business School, University of Oulu, P.O. Box 4600, 90014 Oulu, Finland 


\section{Introduction}

Studies investigating how management control systems contribute to innovation usually show that although control standardizes operations, it is not an obstacle to new product development and innovation (cf. Davila 2000; Ditillo 2004; Bisbe and Otley 2004; Jørgensen and Messner 2009a, b). However, less attention has been given to management and process innovations associated with new ideas and practices that challenge existing patterns of behaviour within an organization (Birkinshaw et al. 2008). Such innovations may stand in contrast to standards and standardization. Standards are established, persistent, rule-bound and measurable processes (Wright et al. 2012 , p.652). They are frequently seen as "the antithesis of innovation" due to the fact that they represent organizational control and regulations (Wright et al. 2012) impeding changes that are new to the state of the art (Birkinshaw et al. 2008, p.829). Moreover, standardization is defined as the result of intentional or unintended actions that generate order by reducing the variety of processes (Wright et al. 2012, p. 652). David and Rothwell (1996) render innovation and standardization as antithetical processes. However, such a view appears to be simplistic, especially when control is considered as a bundle of control practices working together to steer the behaviour of employees in desired directions, rather than as specific and separate controls restricting behaviour (see Ouchi 1979; Merchant and van der Stede 2007). One example of a bundle approach is the levers of control (LOC) framework (Simons 1995). It is explicitly concerned with the simultaneous use of multiple controls (Chenhall and Moers 2015 ) to both enable innovation and to provide constraints on organizations (Mundy 2010).

Recent studies have provided empirical evidence that when different controls have different relative weights in the control system, their combinations support different types of innovativeness (Kruis et al. 2016; Bedford 2015). However, if the combinations do not contain countervailing forces that support different types of innovativeness or both innovation and standardization, innovative capabilities may narrow (Curtis and Sweeney 2017). Similarly, the controlled development of organizations needs both freedom, represented by innovation, and order, provided by standardization. Thus, only the unfettered coexistence of these two forces can ensure "salutary results" (David and Rothwell 1996, p.198). Therefore, it is important to understand how and what kinds of controls may be used in combination to enable the coexistence of both innovation and standardization (see: Gschwantner and Hiebl 2016), rather than focusing on supporting innovations alone by using different levers. The nature of levers may be specifically interesting in the context of lean management, as lean management supports innovativeness and the continuous improvement of processes (Smeds 1994) and requires a standardization of processes (Kennedy and Widener 2008; Fullerton et al. 2013).

This study aims to answer the following research question: How can controls support the coexistence of process and management innovations with standardization in the context of management accounting services? Exploring process and management innovations helps us to enhance our understanding of the nature and interplay of the levers of control, and thus the coexistence of standardization and innovation (cf. Laursen and Salter 2006; Reichstein and Salter 2006). The empirical materials were 
gathered in the lean environment of a business process outsourcing (BPO) company which offers management accounting services to its clients. It provides a good setting for the study, as the organization in question constantly spurs its staff to demonstrate innovative efforts in designing new processes and improving existing ones. At the same time, it employs formal controls and standards to steer and coordinate the behaviour and activities of its employees in order to fulfil the needs of the client. It should be emphasized that the studied company implements the principles of lean management in its operations. Thus, such a setting allows the study of different forms of innovation, as well as standardization. The latter is evident not only in the adoption of lean management at the system level, but is also predominant within the entire organization, as new developments and ideas are accompanied by new organizational standards and controls (Wright et al. 2012). To structure the analysis, the study follows earlier research using the "levers of control" (LOC) framework (Simons 1995) to classify the controls. The study specifically focuses on the nature of levers, i.e. what kinds of controls are used within those levers to enable this coexistence (Bedford 2015; Curtis and Sweeney 2017; Henri 2006; Mundy 2010).

The present paper contributes to the extant literature in the following ways. It examines the relationships between different levers (Mundy 2010; Henri 2006; Bedford 2015), specifically illustrating the nature of the levers of control to explain how the combinations of different levers and controls within them can provide both consistent and countervailing reinforcement, without crowding out innovation or standardization (Simons 1995; Mundy 2010; Curtis and Sweeney 2017). In this way, the study evidences how management control systems can support the coexistence of innovation and standardization of process and management innovations (Birkinshaw et al. 2008; Mol and Birkinshaw 2009; Wright et al. 2012; Gschwantner and Hiebl 2016). Moreover, it improves our understanding of how lean management in professional management accounting services may productively tie the levers of control together (Kennedy and Widener 2008; Fullerton et al. 2013; Tillema and Van der Steen 2015) and further ensure the coexistence of innovation and standardization (David and Rothwell 1996; Wright et al. 2012).

The remainder of the paper is organized as follows. The next section presents the theoretical perspective of the study. Section 3 describes the research design, while Sects. 4 and 5 present an analysis of the empirical findings. The paper ends with a discussion and conclusions.

\section{Theoretical perspective}

\subsection{Management innovation, process innovation and standardization}

Innovation is a broad term describing the adoption of an internally created or purchased product, process, service, program, system, device, or policy that is new to the organization (Damanpour and Evan 1984; Damanpour 1991). The conventional approach sees innovation and standardization as antithetical processes (David and Rothwell 1996; Wright et al. 2012, p. 652) since standardization is defined as the result of intentional or unintended actions that generate order by reducing the variety of pro- 
cesses (Wright et al. 2012, p. 652). The tension and conflictual relationship between the two are discussed in studies that show how innovation is impeded by standardization and bureaucracy. Innovation creating and implementing the new to the state of the art requires diversity and thus challenges existing standards (Birkinshaw et al. 2008) and requires their dilution, as well as looser and more informal organizational structures (Thompson 1965; Burns and Stalker 1961). Placing standards on one side and newness on the other may create some conflicts (Pesämaa 2017). This is due to the fact that standardization results in an organizational momentum and practices that resist change. Such resistance must be overcome in order to implement new management practices (see Rosner 1968, Mol and Birkinshaw 2009, and Wu 2010 among others). Especially in the service sector this standardization can have an adverse effect on innovation as it constrains the contractor-client relationship (Zaltman et al. 1973; Damanpour 1991; Choi et al. 2011). Accordingly, although standardization has been a subject of concern in business for many years, it has only drawn more interest recently (Wright et al. 2012; David and Rothwell 1996). In particular, the relationship between innovation and standardization has been studied as researchers have been interested in determining how much uniformity or diversity should be maintained during the development of innovation (David and Rothwell 1996).

Existing literature further draws a distinction between different types of innovation, such as technical and administrative (management), product and process, as well as incremental and radical (Damanpour 1991). In this paper we focus on process and management innovations. Management innovation is "the invention and implementation of a management practice, process, structure, or technique that is new to the state of the art and is intended to further organizational goals" (Birkinshaw et al. 2008, p. 825). Kimberly (1981) associates management innovation with what managers are and do, as it represents a specific form of organizational change. Process innovation denotes a new element introduced to a company's production or service operations aimed at achieving cost reduction or higher quality (Utterback and Abernathy 1975; Reichstein and Salter 2006). Process and management innovations are important for the development of the organization, as well as its performance and long-term success (Birkinshaw et al. 2008, p. 825). Empirical studies show that both process and management innovations are sparked by improvements in efficiency and attempts at cost reduction (Boer and During 2001; Birkinshaw et al. 2008). These types of innovations influence the entire organization, as they are tightly integrated with other sub-processes within the organization (Tornatzky and Fleischer 1990; Birkinshaw et al. 2008). Thus, they are relatively more complex and difficult to understand than product innovation (Lippman and Rumelt 1982). Moreover, they require an understanding of the organization's work system and must fit into the unique system of the company (Levin et al. 1987).

Process and management innovations have received relatively little consideration in research, as few research papers on innovation have dealt with them over the past 30 years (see: Stata 1989; Crossan and Apaydin 2010; Ganter and Hecker 2014; Damanpour 2014). However, process thinking and management innovation have become increasingly important in recent decades and their impact on the efficiency and competitiveness of organizations has been acknowledged (Womack et al. 1990; Kirner et al. 2011). Such innovations may be directed towards customer demand or 
creating something new just for the sake of novelty. Customer-oriented innovations are often considered more incremental, exploiting existing knowledge (Lukas and Ferrell 2000), while radical innovations lead to substantial changes in the activities of the organization and alter existing practices (Damanpour 1991). Moreover, companies should exploit their resources to generate earnings and at the same time explore new opportunities and resources, in order to introduce radical innovations for the long-term survival of the organization (Gschwantner and Hiebl 2016). Still, the radicalness of innovation is relative, as the management models (TQM, BPR, Six Sigma) popularized as best practices that emphasize incremental innovation for a specific manager or organization may be viewed as radical (Hage 1999; Rogers 2003; Mol and Birkinshaw 2009; Wright et al. 2012).

It should be noted that attempts to change production or service processes, for example by implementing lean management, may also be defined as management innovation (Baer and Frese 2003). In line with this, companies use lean techniques to minimize waste in the processes, to produce and deliver quality products, and to facilitate decision-making and control (Kennedy and Widener 2008; Van De Ven 1986; Helander et al. 2015). Interestingly, when the implementation of lean management is defined as a process and management innovation, we face a contradiction between innovation and standardization. This is because standardization is an important element in lean management, necessary to manage the increasing variety of processes and products, as well as to perform continuous improvements. Lean companies actually use rigorous standardization in order to provide both flexibility and predictable outcomes (Kennedy and Widener 2008; Fullerton et al. 2013). Standards are "established, persistent, rule-bound and measurable processes" (Wright et al. 2012, p. 652). They reduce uncertainty, while the implementation of simplified procedures enables the archiving and enactment of specialized skills, resulting in increased efficiency, productivity and reducing costs (David and Rothwell 1996).

Based on the review above, the popular juxtaposition of standardization and innovations is rather simplistic. This derives from the fact that innovation is frequently associated with radical change and gaining a competitive advantage through novelty (Wright et al. 2012). However, newness is relative and some ideas may be popular in general, but for a specific organization can be innovative (Rogers 2003; Mol and Birkinshaw 2009; Wright et al. 2012). The diffusion of new management models and trends (e.g. Six Sigma, TQM, increases the standardization and commonality of business practices (Wright et al. 2012). Some of them frequently rely on standardization (Wright et al. 2012). Many modern organizations develop standard processes in order to attain coordination for both increased efficiency and innovativeness (David and Rothwell 1996). The implementation phase of management innovation in particular requires standardization, as new ideas should be supported by new organizational standards and practices (Worren et al. 1999; Courpasson 2000). Especially in highly innovative companies, the risk of dysfunctional behaviours associated with employee creativity calls for effective control (Grabner and Speckbacher 2016). But even companies with a high degree of stability resulting from standardization and efficiency may shape managerial innovation in many ways (Janka et al. 2019). Moreover, standardization is known to be conducive to incremental innovations as it enables experience to be gained in standardized operations, from which employees can learn directly (learning 
by doing) (Benner and Tushman 2003). This broadens the sphere of application for what has been observed and experimented with. Incremental learning and experimentation in turn gives positive feedback for future modifications and the optimization of procedures that can lead to further standardization (David and Rothwell 1996). Thus, the incremental change to standardized practices results in the perception of innovation as reinvention over time (Rogers 2003; Wright et al. 2012). Because of this less than straightforward relationship between standardization and process and management innovations, our understanding of how to support them both with the help of controls is yet underdeveloped. In the following section, we describe the framework we use for our study.

\subsection{Levers of control framework}

In order to study the elements of a management control system, we used the LOC framework (Simons 1995), which is most widely used in accounting literature (Strauss and Zecher 2013). Although the literature offers various frameworks for assessing management controls (Ouchi 1979; Flamholtz 1996; Otley 1999; Merchant and van der Stede 2007; Malmi and Brown 2008), the LOC framework underlines the importance of considering multiple controls collectively (Chenhall and Moers 2015). It has been widely used to study the problems of managing creativity and innovations (cf. Bisbe and Otley 2004; Henri 2006; Bisbe and Malagueño 2009, 2015; Mundy 2010; Bedford 2015; Curtis and Sweeney 2017), mainly through the interactive and diagnostic use of management control systems (Lövstål and Jontoft 2017).

Simons (1987) defines management control systems as formalized procedures and systems that use information to maintain or change patterns in organizational activity. Simons' levers of control framework (1995) distinguishes three types of control system: a belief system, a boundary system, and a feedback and measurement system. A belief system is "the explicit set of organizational definitions that senior managers communicate formally and reinforce systematically to provide basic values, purpose, and direction for the organization." (Simons 1995, p. 34). Beliefs are intended to encourage employees to pursue behaviour in line with organizational values and objectives. Organizations operating in uncertain conditions may also use a belief system to communicate strategic goals to employees, enabling them to match their behaviour to expected outcomes (Speklé 2001), as well as to inspire them to search for new opportunities and solutions (Mundy 2010). A boundary system "delineates the acceptable domain of strategic activity for organizational participants" (Simons 1995, p. 39). It is aimed at allowing employees to perform their tasks within a certain predefined area (Adler and Chen 2011). By communicating which activities are acceptable and unacceptable, companies aim to steer initiative to a "meaningful end-point" and prevent employees from wasting organizational resources by seeking constant improvements and time-consuming solutions (Mundy 2010). Both the belief and boundary systems motivate employees to search for new opportunities, but the first way is "positive and enabling", while the other is "negative and coercive" (Simons 1995).

Feedback and measurement systems are used to implement and elaborate on strategy, as well as to adapt it to a competitive environment. However, Simons underlines 
the importance of the style of the control systems used, recognizing two ways of using feedback and measurement systems: as a diagnostic control system and an interactive control system (Simons 1995, 2000). Diagnostic control systems are "the formal information systems that managers use to monitor organizational outcomes and correct deviations from pre-set standard performance" (Simons 1995, p. 59). They measure ex post the results of employees' actions and are used to monitor employees, motivate them, and align their behaviour with organizational objectives, which include employees finding novel solutions. Interactive control systems are "used by senior managers to stimulate dialogue and debate about strategic uncertainties" (Simons 1995, p. 193). They are aimed at communicating organizational priorities and stimulating the development of new strategies (Adler and Chen 2011). The systems help to gather together all individuals with different sets of information about the company's activities (Speklé 2001), thus enabling mangers to obtain local knowledge and exchange information (Ahrens and Chapman 2004; Wouters and Wilderom 2008). These two control systems are used to formulate and guide the implementation of strategy.

The management control field has long focused on the study of the relationship between the innovation and various individual levers at the company level (for the literature review see Mol 2015 and Fried 2017 among others). Bisbe and Otley (2004) prove that the interactive use of control systems positively influences the relationship between product innovation and performance, while Lopez-Valeiras et al. (2016) confirm this influence on process and organizational innovation. Interactive use of budgeting also enables middle managers to act in an innovative manner (Linder and Torp 2017), but the interactive control mechanisms used by senior management depend on the specific form of innovation (Bisbe and Malagueño 2009).

But Simons himself states that only a combined use of levers creates a "tension between opportunistic innovation and predictable goal achievement that is essential for positive growth" (Simons 1995, p. 153). It underscores how the countervailing but interrelated elements of a control system may work together for both standardization and innovation (Lewis 2000; Henri 2006). LOC provide an information-rich organizational work environment enabling encouragement and opportunities for the development of new ideas but within a clearly defined space. Thus, it ensures both autonomy support through beliefs and interactive controls, as well structure through diagnostic and boundary controls (Speklé et al. 2017). The relationships between "positive" (beliefs and interactive systems) and "negative" (boundary and diagnostic systems) levers foster open discussion, allowing employees to group their ideas and activities, in addition to integrating theoretically opposed concepts (Henri 2006). Existing research recently has focused on how the combinations of different control levers may help innovation (Henri 2006, Widener 2007, Mundy 2010, Bedford 2015, Kruis et al. 2016, Curtis and Sweeney 2017, and Janka and Guenther 2018, for example). Henri (2006) suggests that a management control system used in an interactive way contributes positively to the development of capabilities of innovativeness, but when used diagnostically, it exerts negative pressure. The combined use, both in a diagnostic and interactive fashion, influences the above-mentioned capabilities. Further studies show that this combination is important for the simultaneous aim of incremental and radical innovation (Bedford 2015). Moreover, investigations on a set of four control systems revealed that organizational learning is positively associated with 
the belief system and the diagnostic use of performance measures (Widener 2007). According to Mundy (2010), consistency in the use of multiple controls collectively simultaneously enables creativity and provides constraints on organizations. But Curtis and Sweeney (2017) point out that consistency in such combinations may result in shorter-term innovation projects crowding out longer-term value creation. The above discussion indicates that innovations may need some level of standardization (Rogers 2003; Wright et al. 2012); however, its effect on innovativeness remains unclear (Janka et al. 2019).

An interesting relationship may also arise between lean and traditional controls in a lean management context (Tillema and Van der Steen 2015). While lean management supports innovativeness and the continuous improvement of processes (Smeds 1994), at the same time its principles introduce rigorous standardization supported with controls. Therefore, lean management emphasizes the combinations of different controls (Kennedy and Widener 2008; Fullerton et al. 2013), such as the participation of lower levels in decision making, the non-financial nature of information, and the higher frequency of information dissemination (Tillema and Van der Steen 2015). However, it may create conflicts between the traditional controls and lean controls that are introduced by lean management principles (Tillema and Van der Steen 2015).

Against this backdrop, it is important to study the nature of the levers, i.e. exactly how and what kind of controls are used to support the coexistence of both innovation and standardization, rather than focusing on the level of the levers in general and how their combinations spur innovation (Curtis and Sweeney 2017). Solely focusing on the controls' role in encouraging innovation may undermine the need for coexisting innovation and standardization. Consistent reinforcement creates a push for consistency in controls enabling a crowding-out effect, focusing either on innovation or on standardization. The positive and negative forces prevail in countervailing reinforcement, which is required for longer-term value creation (Curtis and Sweeney 2017). A management control system that contains countervailing elements reduces momentum in one particular direction. However, we do not have a detailed account of the nature of control levers and how they may actually be used to support both consistent and countervailing reinforcement (Curtis and Sweeney 2017; Gschwantner and Hiebl 2016). Moreover, the current research is concentrated on product innovation, neglecting process and management innovations. As a result, both Bedford (2015) and Curtis and Sweeney (2017) have called for an examination of the controls used for other types of innovation-not only product innovation-as well as for a deeper understanding of the relationships between those controls.

\section{Research methodology}

In order to understand the nature of the levers of control that are necessary to enable the coexistence of innovation and standardization, this paper adopts a case study method as recommended by earlier research (see Curtis and Sweeney 2017, among others). The data for the present study was collected in Cube-a department of a large business process outsourcing firm (BPO) located in Central Eastern Europe that employs more than one thousand accounting and finance professionals on site. The department in 
which this study takes place provides the most advanced service in the portfolio of company. Employing around one hundred accountants, it is responsible for delivering management accounting services that have been transferred from the client, including managerial reporting, budgeting, transfer pricing, and performance evaluation. The volume of activities carried out in the management accounting department is substantial, as over seven thousand reports are prepared each month by Cube for more than seven hundred entities. The constant pressure on cost and process improvement has resulted in the introduction of lean management in the organization, which started in 2015.

The data consists of twenty-two interviews, presentations, and internal documentation given to the researchers. The data collection was enriched by observations made during visits to the company in order to observe employees in a natural setting and to identify the controls. The collection of empirical material took place in 2016-2017. All the interviews and presentations were recorded, transcribed and translated into English, as some of them were conducted in the local language. Two researchers or more were present during each interview. The semi-structured interviews lasted between 30 and $130 \mathrm{~min}$ and covered different organizational levels and positions. The details of the interviews are in the Appendices. The interview guide was structured and the themes were defined, but the final content was shaped in the course of every interview. Respondents were asked about their educational background and earlier professional experience, about the nature, methods and organization of their day-today work, details of projects completed, as well as their perception of the organization and its controls. Interviews were supplemented with reports, procedures, instructions, agreements, code of conduct, process maps, competency matrices, and score tables provided by the respondents. Two presentations were important for the triangulation of the research. The first presentation of the firm led by one of the senior managers helped gain an understanding of the organization of the company, specific to business process outsourcing, and the major concepts behind its existence and operations. The second presentation on lean led by three senior managers discussed lean principles and details of their implementation. During the presentations, the participants answered questions asked by researchers. Working with the company for almost 2 years allowed us to observe employees working on different projects, as well as performing their daily activities. The researchers' observations were gathered in the form of written field notes prepared after each visit to the company.

The transcripts of interviews, field notes and additional internal documentation resulted in rich and detailed qualitative material. The analysis was conducted in the following stages. First, each member of the research team read the materials independently, focusing particularly on the management control system and the relationship between innovation and standardization. Next, the first author identified the levers of control using the research material. Finally, the entire research team analysed whether there were interactions between the levers and if and how these interactions support the coexistence of process and management innovations with standardization. The separated controls were studied in order to detect their nature as well as the combinations of different levers that occur in the organization. As a result of this analysis and discussions within the research team, the researchers began to understand how the levers worked together and reinforced one another, influencing the relationship between 
innovation and standardization. As abductive reasoning was used, where empirical observations continuously redirected the theoretical view and vice versa (see: Järvenpää 2007) the concepts of consistent and countervailing reinforcement introduced by Curtis and Sweeney (2017) were finally used to explain and highlight the important findings in the data. While these analytical steps and the discussions within the research team did not follow a clear structure that can be depicted retrospectively, they resulted in the patterns described in the following section and summarized in Table 1 in Sect. 5.

The setting of the study describing innovation, standardization and the management control system, as well as the relationship between them, is further discussed in Sects. 4 and 5 below.

\section{Empirical analysis}

\subsection{Standardization, process and management innovations in BPO}

Although BPO is identified with standardization, which requires effective control for efficiency, searching for new ideas is crucial for the long-term survival of Cube. The pressure to look for process innovations stems from the manifold circumstances faced by Cube and its management; they are all stimulated by the search for efficiency and quality, as well as cost reduction.

We've got many cases showing how we have already improved [processes]... but currently we are pushing for even higher savings and better quality. So quality is the highest priority. This is a never-ending story, we know... Currently, we need to cut costs by $40 \%$ for [name of contractor]. (Senior Manager 3)

Our aim is to transform the process so that the process is more effective, more efficient. (Process Manager)

Process innovations present in Cube can be placed on a continuum from incremental to radical. The most incremental innovations pursue cost reductions by developing and improving the client's processes that have been transferred to Cube and are managed by them, or which they want to eventually be transferred. Currently, Cube manages, among others, processes connected with reporting, transfer pricing, budgeting and variance analysis, and rebate calculations for its clients.

Transferring a new process from a client to Cube frequently requires major changes to the process or its complete reconstruction and thus more radical innovation. Some processes are designed "from scratch" by Cube, with more cooperation from the contractor's side. Employees responsible for this process collect data from different sources and suggest new solutions or ways of organizing the transaction. Then the process is standardized, automated, and transferred to all the contractor's premises.

To arrive at the present, standard accepted by the client, we had to prepare about 100 versions of each report that were discussed with them, improved and changed, and finally accepted. The final version is a result of many hours of joint discussion (between the client and ourselves) and consultation with the client. 


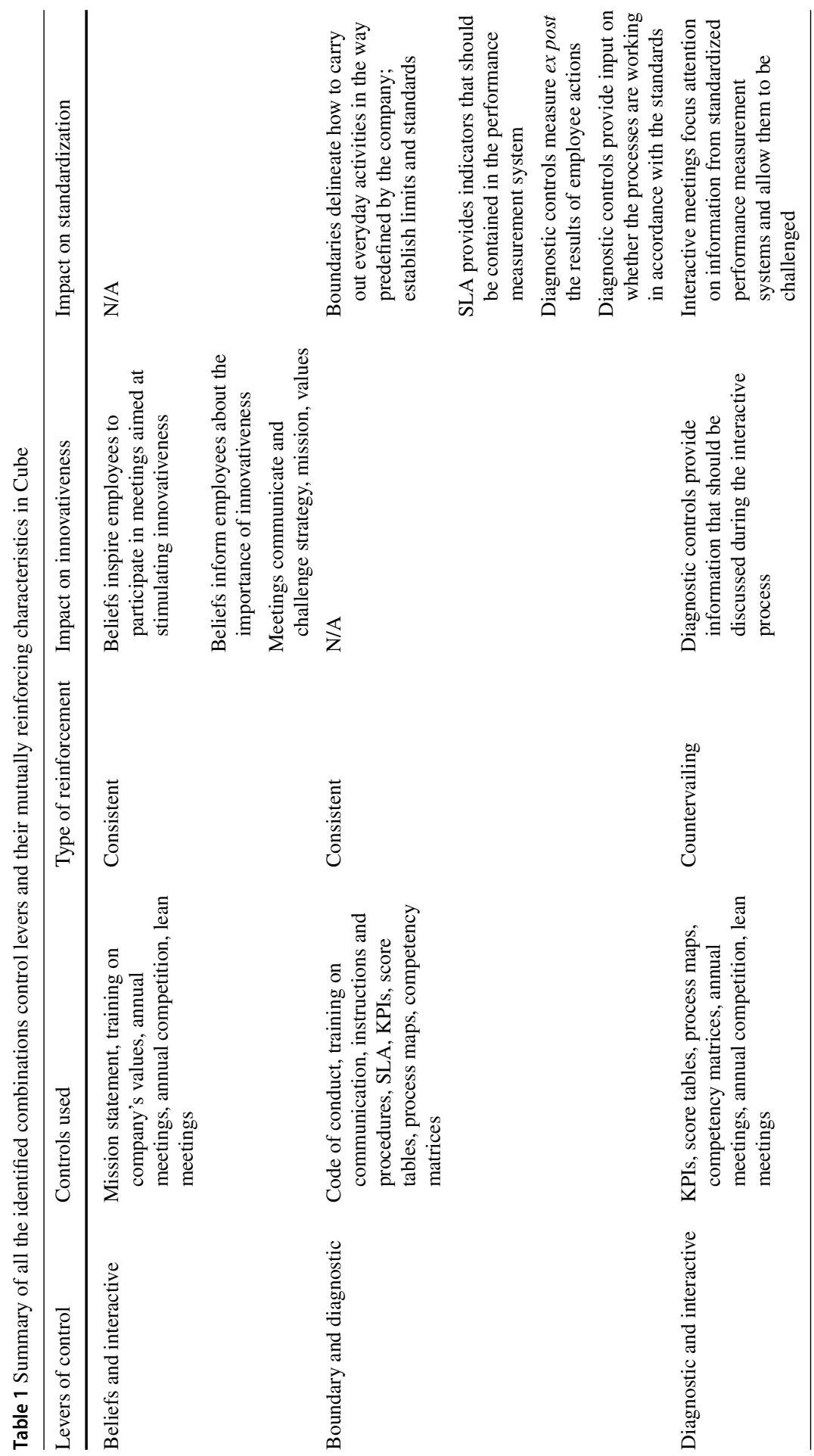




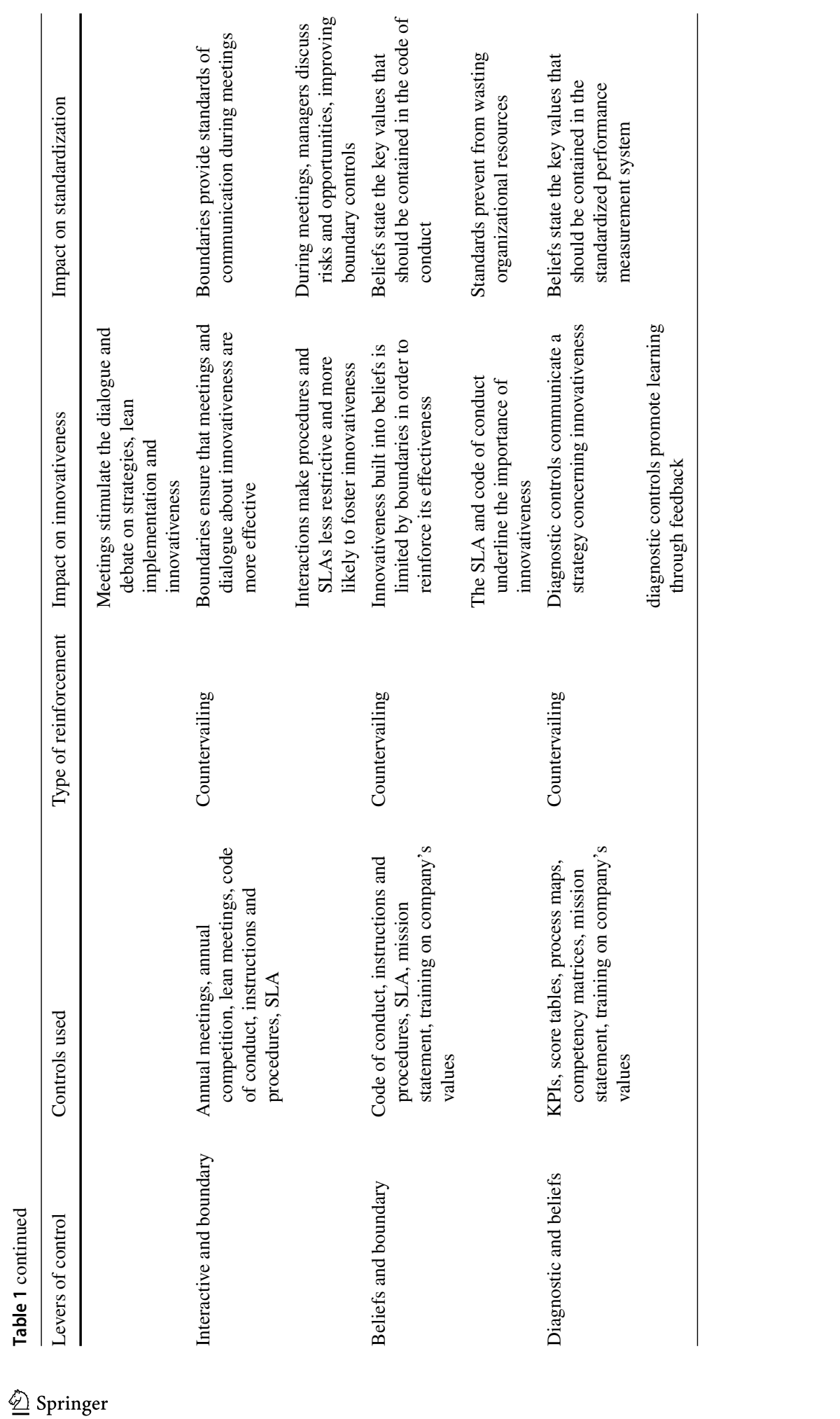


We not only give them technical support, but also advice on what it should look like. (Process Specialist)

One example of process innovation is designing the Reporting Center that produces different types of managerial reports for more than eight hundred of the client's sites all over the world. This project required the creation of a coherent concept of reporting in different business areas, such as controlling marketing expenses or sales analysis, elaborating on templates of reports, consolidating data from multiple resources, integrating IT systems and administering them, as well as delivering reports on a regular basis to clients. Once the process of design was finished and the project was tested in one of the client's sites, the process of harmonization and standardization started. Each manual step in preparing and refreshing reports was removed and reports were automated, and finally the main standard template was replicated in all the client's sites. Implementation of the standardized reporting processes throughout the whole multinational company allows harmonization of reporting processes and facilitates their preparation, consolidation and analysis. Standardization reduces the complexity of reporting and facilitates comparisons in a global context, in addition to accelerating report preparation times and ensuring their high quality. Although the innovation and standardization were successfully implemented, still the Reporting Center requires constant improvement and maintenance provided by Cube in accordance with client expectations, the changing business conditions and pressure on cost reduction. The requirements are not always clear-cut, but the clients desire a solution that Cube's employees can only execute once they themselves have devised it, which demands innovativeness. This creates a cyclic relationship between innovation and standardization, as standardized and stable processes are reinvented and substantially transformed, in turn requiring the standardization and replication to be repeated. As a result, the pressure on employees to change the ordered processes while working simultaneously on innovation and standardization results in the challenge of harmonizing innovation and standardization.

You constantly have to think how to improve what is in theory working perfectly well now. (Process Manager)

Every change and improvement results in additional work for us, we have to understand the changes, implement them into reporting and instruction, learn and replicate them. Sometimes it can even take six months before the report is standardized and "mature". The more complicated the process, the more work it requires. [...] The accumulation of work in reporting is also stressful. (Management Accounting Specialist 1)

Accordingly, standardization and incremental innovation are intertwined. However, such standardized and automated services often narrow the duties of Cube and its employees and lead to a reduction in the headcount necessary to manage the process. As a result, more innovativeness is required and Cube is forced to constantly seek new opportunities and services to offer to clients. Receiving more "high end" processes from the client to be outsourced seems to be one of the most important issues for the managers and employees in Cube. 
With all this automation and improvement, we end up cutting the branch we're sitting on. (Senior Manager 3)

This creates a further, rather supportive relationship between innovation and standardization. There is the danger that when the processes are finally automated and standardized they will be of no value to the client. Thus, paradoxically, standardization spurs attempts to innovate among employees and managers.

I look at our clients for management accounting processes that we can transfer to Cube. Every year we have to provide substantial savings to each client according to the contract, so we have to actively look for new solutions or processes that we can improve, or find methods of harmonization. We must prove that we are able to do our work better, quicker, cheaper. (Senior Manager 3)

Generally, the process innovation is formalized under Cube's Process Improvement Program, whose aim is primarily to stabilize and standardize transactions, then continue with the implementation of improvements, and finally concentrate on seeking innovation and providing consultancy to the contractor. The Process Improvement Program is itself an innovation which Cube plans to have patented. As a process innovation, it belongs to the more radical end of the continuum of innovations in Cube. One of the senior managers describes the details of the Process Improvement Program in this way:

We divide the operation phases into three stages, which we call 'maturity levels'. Once the transfer of the operation from the client is complete, we have to learn how to perform the operation. We say that this is the first stage, a so-called stable operation, a noiseless process, one without any escalations on the client's side. But of course, this is not the last stage. What we do in the second step is to implement the best practices [...] to optimize the process according to our internal capabilities, so that we can improve productivity, reduce variances and optimize as much as we can. And the last stage is the creation of business value added for the client, so bringing about a more effective, more efficient transformation to the process, as for example in the case of the Reporting Center." (Senior Manager 1)

A less incremental, but customer-oriented group of management innovations is related to the new elements introduced to the internal operation of the organization, such as lean management and new IT technologies, which are aimed at improving Cube's internal processes, eliminating waste, and increasing efficiency. Clients expect substantial savings, which requires the constant improvement of internal processes. Lean management, in particular, represents a substantial change in the activities of the organization and a departure from existing practices. Its introduction together with the concept of continuous improvement aims to optimize the process and eliminate all waste and inefficiency. Lean's long-term goals are increasing productivity and revenue, as well as developing people and processes. Achievement of these targets is measured within three areas: people, efficiency and growth. Lean strategy is supported by two important pillars: managing processes end-to-end and value for the client. This element of lean strategy requires the mapping of every process, as well as measuring 
the added value of each one. The foundations of the strategy are goal congruence, awareness, and engagement.

[Lean implementation] is something special for such a service entity as we are. We are quite advanced in introducing this program. This is because we want to make more savings for our clients. Now, in lean, we are able to monitor the work in each department, and how much time we need for each activity and process. We are looking for inefficiency (muda in Japanese) and waste, and we try to eliminate it. We've found lots of inefficiency. (Senior Manager 2)

Due to lean strategy, all the managers and employees are engaged in troubleshooting problems, improving the process flow, and making decisions on quality. Meetings and discussions take up to 50 per cent of employees' time, which could be otherwise spent on actual value-adding reporting and improvement work. Thus, Cube's employees are forced to juggle the latter with innovative work that does not add value or cut costs immediately, but aims to effect longer-term developments. In addition, lean brings standardization and new methods of control, creating extra work for ordinary employees.

Lean makes me sick, all those measurements, tables we have to fill in. All the time there are changes to make the processes stable. (Management Accountant 1)

We have lean and kaizen, but for me it is difficult to implement. I was working on a new project where there was a lot of ad hoc work, so we couldn't standardize it. (Process Manager 2)

Additionally, senior management is aware of the fact that a substantial cut in the cost of the process can be achieved by developing and introducing new sophisticated IT tools. Such activities are challenging to Cube's employees as they are not traditional tasks of management accounting, but belong to a broader category of management improvements outside its own core competencies.

To all intents and purposes, we have become an IT team, preparing templates, changing them, looking for data in different systems, maintaining systems. It is no longer management accounting. (Senior Manager 1)

\subsection{Nature of control levers in Cube}

\subsubsection{Belief system}

Beliefs are communicated in Cube's mission statement and they are visible in company documents, e-mails and on its website. The focus on 'client value, leadership, innovation, and excellence' is present on the first page of the company's website, above the main entrance to the building, on huge posters on the walls of the most important rooms, as well as in the footers of business e-mails, letters, or any document printed within the company. Moreover, every new member of the organization takes a 6-h training session on the company's values. 
[Before starting my job] I had a standard set of training sessions about Cube and about our values, strategy, and aims, about job security, the code of conduct, and then also on soft skills - professional communication with clients and good work organization. But the first training session is always on values. We must know them! (Management Accounting Specialist 1)

The mission statement and training sessions communicate clearly the organizational goals and values to be internalized by employees in the organization. Leadership, innovativeness, value for the client, and excellence would appear to indicate the values important to the company and suggest the creative nature of necessary action promoted by the company.

\subsubsection{Boundary system}

The boundary system is present in Cube in the form of a code of conduct which carefully indicates what behaviour is permitted and what is prohibited. Moreover, all employees starting their career in Cube receive training on how to communicate with clients and colleagues in the way established by the company. The training sessions. in particular communicate the clearly acceptable and unacceptable activities in organizational life.

Initial training (the introductory session) is similar for all employees. [...] I especially appreciate those workshops on communicating with clients. Yes, communication and relationships with the client are the most important for my current position. (Business Analyst)

Interaction with clients in particular is carefully delineated by the code of conduct and training on communication. This is because communication with clients is open to regular employees and all management levels, from senior managers to the lowest level specialists providing clients with simple services. Moreover, middle and low-level employees from Cube are frequently in contact with the middle or senior managers from the client companies, e.g. Group Financial Controllers or Divisional Managers.

You see there are [our] different levels [that] communicate with the different levels of the client's people. So, we've got chief accountants, our team leaders, [...] the people responsible for the client's side, with our people responsible on our side. So, communication is always open. At the top level you see, for example, [the name of one of the client's senior managers], so also high level [managers] talk to our people [...]. The channel of communication is open for all parties. (Senior Manager 2)

Detailed procedures and instructions are important elements of the boundary system, providing quality and consistency in the services offered to the client. For every process and service, a complete set of steps exists, which is necessary to follow in order for a backup employee - or any other person-to carry out the process. Each instruction is created together with the client and its final version requires the client's approval. Although the instructions are strict, and preparing and updating them is time-consuming, employees have found them to be an essential part of their work. 
Oh yes, instructions are important for me, I use them even now, because I do not want to miss something. I can be certain that everything is correct. It is written in the instructions, step by step: click this cell, paste the data. I don't know about the others, but I use instructions all the time. (Management Accountant 1)

We have a rule in Cube: everyone uses instructions. I have mine, I must update them if there are any changes, and I use them every time I prepare my reports. Instructions are extremely valuable for me. (Management Accountant 2)

The Service Level Agreement (SLA) constitutes an important boundary control. It describes all aspects of the services offered to a particular client, including quality, availability, and the responsibilities of each party in the contract. Directors use the SLA in order to provide both a complete overview and guidelines for the required results of each process and service. The SLA helps to establish limits within which managers and employees are expected to perform.

In the SLA, there are a number of important elements [...]. Should problems [with executing the SLA] arise, we can have penalties imposed on us. But it never happens. (Senior Manager 2)

Compliance and adhering to the SLA are seen by managers and employees alike as the most vital part of their work. Senior managers treat the SLA as an informative tool that provides them with local operating knowledge. The SLA is supplemented with a database known as Master Data, which lists details on each report or service provided to the client. It contains the frequency of reporting, the recipient of the service, and a link to instructions for the service or process.

\subsubsection{Diagnostic control system}

In addition to boundary controls, the processes are monitored via the diagnostic use of a performance measurement system, whose aim is to translate strategy into measurable success factors and measure the results of employee actions ex post. The performance measurement system in Cube embraces four areas that represent the critical success factors of the organization and allow managers and employees to focus their attention on them: adhering to the SLA, the personal development of employees, lean implementation, and assessment by the client. For every area, targets are set, and any deviations from the plan are carefully monitored. The performance measurement system tracks progress towards goals, monitors results and compares the outcomes to expectations, as well as reviewing key measures.

The Key Performance Indicators (KPIs) incorporated into the performance measurement system to monitor the SLA are on time delivery, the number of errors, and the cost of hours invoiced. Senior managers also have targets for revenue generated, profit margin gained, and retention rate.

My main targets are the quality of my work (number of errors), meeting work deadlines (on time delivery of reports) [...]. (Process Manager)

My targets [are] revenue, profit margin-those are financial, but I have also personal ones-how many people leave my team: if many, it is bad. (Senior Manager 1) 
Personal development targets create an important part of the evaluation process, as they are aimed at helping employees to develop themselves. Employees are required to choose external and internal training sessions necessary for different stages of their career, focusing on core, unique, or lean skills, as indicated in the competency matrix for their position. The performance measurement system verifies if these targets are attained.

There is a special website, and you can check what training sessions there are for each level and position, which training sessions are obligatory and which are voluntary. (Management Accountant 1)

Assessment is made by clients twice per year. Every employee who is in contact with a client receives marks from one to ten for different areas of cooperation. The elements taken into consideration are adherence to deadlines, engagement, and improvements made to the process. This system of assessment covers all employees, including middle level management. The results of the assessment are discussed by a manager with the employee.

Our colleagues from the client side also give "marks" [...] based on whether reports were on time, how we improved a process, if we were engaged in the process, if we suggested changes to the processes. They send their marks to our manager and our manager informs us. (Process Executive)

Lean targets are focused on the value added and the productivity of the processes. They contain non-financial indicators: the number of problems solved per person, the value added to the process, and time spent on a transaction. The introduction of lean management expanded diagnostic controls through the use of diagnostic lean controls, such as process maps, a competency matrix, and score tables. Process maps provide a visual representation of all the activities within each process, helping to reduce waste and increase value to the clients. They measure the processes and compare the activities with the desired output aligned with the company's values and capabilities.

A process map describes the process step by step: what activities are in this process, how to get data, how long it takes etc., and we try to find inefficiency and waste in this process and we look for improvement. (Senior Manager 2)

A competency matrix is created for each employee and position. This control is designed to measure and assess the core, unique, and lean skills necessary to carry out relevant activities. A set of expectations that the employee needs to meet are indicated and the development of individual skills is monitored.

For better HR management, we introduced competency matrices. Processes are more and more complicated, so we must invest in workers' skills and competences. In order to solve problems and look for new solutions they must have the knowledge and skills. (Senior Manager 2)

Finally, score tables help to monitor the operational and financial impacts of improvements. The first part of a score table contains the hourly reporting and productivity targets of each employee. The second part includes the KPI targets. All team 
managers are allowed to indicate their own targets for KPIs, but quality, time and productivity are required elements for every table.

Currently all our workers [...] prepare a detailed analysis of their activities and the time spent on them. Every day, every hour [...]. Thanks to this, we can now observe trends and improvements in those activities that add value, and a decrease in non-value adding activities. (Senior Manager 2)

Employee performance evaluation is biannual and also contains self-assessment and a discussion with a manager about its results. Each variation from targeted indicators versus actual performance is analysed by the employee and the functional manager, and improvements to adverse variances are planned. The evaluation system is connected with the bonus system, as well as future promotion and job rotation. Employees thus treat it as an important part of their work.

You can have: a 'satisfactory' result, 'better than satisfactory', 'less than satisfactory' or 'outstanding'. If you have 'less than satisfactory', you will not receive a bonus for half a year. Those who have received an 'outstanding' result more than twice will probably be promoted sooner or later. (Senior Business Analyst)

\subsubsection{Interactive control system}

The feedback and measurement system is also used in Cube in an interactive way, which means that operating and senior managers pay regular (daily, monthly, and annual) attention to it and exchange information with employees. They are actively and frequently involved in interpreting, monitoring, and discussing information from performance measurement systems on the results achieved and the decisions made. An essential part of the interactive process is regular meetings and discussions between senior and operating managers and employees. These are mainly annual meetings; daily and monthly lean meetings aimed at discussing different performance measures are referred to further in the text as interactive meetings.

During the annual meeting, directors provide each employee with information on the strategy, mission, values and goals, and present the major financial company results against the targeted ones-primarily sales revenue, net profit, and profit margin. As the long-term goals of the organization are not only to increase productivity and revenue but also to develop people and processes, senior managers show the actual achievements in those areas: the percentage of SLA targets achieved and the increases in employee competences.

Well, these [annual] meetings are aimed at communicating our strategy and targets. (Senior Manager 1)

In addition, Cube organizes an annual competition for employees to demonstrate their knowledge and understanding of the current strategy and how they can participate in its realization. They are asked to suggest suitable indicators that could measure the realization of the strategy at their level, which could then be incorporated into the performance measurement system. In this way, senior managers involve employees in 
the design of the performance measurement system itself in order to share information and reduce the knowledge gap.

We organize competitions and quizzes for our employees- 'How do you want to realize the strategy?' We ask them to explain how they understand targets and what they mean to them?' We received 300 answers and we chose the five best, in our opinion. (Senior Manager 1)

The implementation of lean management enriched the interactive control system with new interactive lean controls such as daily and monthly lean meetings. The results from score tables are analysed and discussed during a lean meeting held every morning by the managers of each department. Every member of the department participates in these lean meetings. The monthly results from the score tables are presented in aggregated form to senior managers then discussed with them at the monthly lean meeting. Both the daily and monthly lean meetings aim to support lean implementation and improve processes by joint collaboration.

Every day we have a lean meeting with different lean teams in order to discuss their improvements. (Senior Manager 1)

\section{Simultaneous use of levers: enabling the coexistence of innovation and standardization}

As the previous section indicates, all the levers of control in Cube are simultaneously used, combining their elements in a reinforcing whole (cf. Simons 2000). Since the control system contains countervailing controls, the nature of the levers and their use is analysed in more detail in this section to illustrate how mutual reinforcement becomes both consistent and countervailing, thus balancing between searching for new opportunities and effectively controlling the existing, efficient, standardized processes (Curtis and Sweeney 2017). In general, employees from all levels in Cube are engaged in innovation-seeking activities for clients and internal processes; all these processes are carefully monitored.

And if there are improvements, then we also reward people. [...] We give rewards, we instill pride in those people. [...] So how do we do these things [process innovations and improvements for clients]? Lots [of SLAs], many agreements with the customer, procedures, how we should provide quality, what the deadlines for particular reports are... All this is written in stone, so to speak [...] because we need to 'live' it. All these things and [everything that was] agreed with the customer are written down in [Cube's] KPIs, too. (Senior Manager 1)

The "positive" levers of control are clearly related in Cube and they focus on innovativeness. Cube's beliefs are aimed at inspiring employees to participate actively in interactive controls and contribute to the strategy. On the other hand, meetings which present values and strategy in Cube are an important element of the control system, underlining the importance of innovation as a core value. Daily and monthly meetings are time-consuming for managers, but they are important for the teamwork 
and problem solving element. Directors try to combine the beliefs and interactive controls, engaging themselves and all the employees in learning about the strategy, uncertainties, engagement and innovation (see Simons 1995).

Every day we have meetings with different team leaders in order to discuss problems in the team concerning innovation and solutions. (Senior Manager 1)

The regular interactive meetings play an important role in identifying and generating new initiatives in order to achieve the organization's objectives. They enable discussion between managers and employees on strategic challenges, provide a shared view of the organization, and tie it together through the shared focus on Cube's values that represent beliefs (cf. Simons 1995). It is evident in the talk of employees representing various levels of management that meetings are an important source of innovative ideas.

I have the power to influence many decisions, suggest new solutions, and implement new ideas. There is great flexibility, and we can thrash out together how the innovation should look. (Process Manager 1)

The "negative" controls aimed at standardization also work together. Diagnostic controls (the performance measurement system, score tables, process maps, competency matrices) are combined with boundaries (the code of conduct, instructions and procedures) as the directors seek to reduce the risk of opportunistic behaviour and information asymmetry while controlling the process and its results in order to fulfil the requirements of clients in a standardized way. The comment below illustrates that boundaries (procedures) and diagnostic controls (process maps) are frequently combined in order to support the improvements of processes.

Harmonization and automation need procedures. The rules and principles [...] as well as mappings must be clear. (Process Manager 4)

In accordance with Simons (1995, p. 47), Cube uses diagnostic control systems to pressure employees, while strict standards make clear that certain undesirable behaviours will not be tolerated. The SLA is a specific control, which contains elements of both boundary and diagnostic systems, providing elements required by clients that are then encompassed by the performance measurement system.

[In SLA] there is important information that shows what we measure, how we measure it, how much it has to be in percentage terms, how many reports must be uploaded on time, how many errors are acceptable: everything is explained there in detail. This is a control tool between them [the clients] and us. The SLA gives our clients security and assurance that we will work appropriately and add value. (Senior Manager 1)

The above-mentioned combinations of levers are mutually reinforcing but consistent, as the first pushes for consistency in innovation, while the second focuses on standardization. However, the role of the positive and negative elements in constructing countervailing reinforcement is also visible in Cube (cf. Curtis and Sweeney 2017). The relationship between the diagnostic and interactive systems is extremely important, as operating in tandem these levers reinforce the positive effect of the 
interactive system on innovation (Henri 2006; Bedford 2015). The ability to integrate diagnostic and interactive levers constitutes an important organizational capability in Cube, inducing innovations in a highly standardized environment (cf. Henri 2006). The interactive processes play an important role in Cube, as they not only provide information but also integrate the strategic and operational perspectives necessary for the development and implementation of innovative solutions. Regular meetings stimulate dialogue on new solutions, focus attention on innovative effort, and inspire creative leaders, but they are monitored by a standardized diagnostic control in the form of the performance measurement system. Targets and standards are clearly stated to employees, but the diagnostic system is moderated by workshops and meetings explaining the aim of controls, thus supporting innovativeness. The comment below suggests that during interactive meetings, innovation and improvement targets are not just presented to employees but also discussed with them in order to support problem solving. Senior managers are engaged in these activities, actively participating in discussions on changes to the processes.

[...] Targets [on improvements and innovation] are precise and personalized. [...] We try to explain the idea of them to our employees, and we are happy because they are not afraid now to say, 'I do not understand [my target], help me to do it correctly!' We prepare workshops for employees [aimed at discussing with them] how to define targets and map a process, and how to change the process and define the roles in the process. (Senior Manager 3)

Regular interactive meetings also aim to stimulate dialogue and debate among employees. These controls focus attention on the performance measurement system itself and allow it to be challenged. This "positive" element in the use of a standardizing diagnostic system thus makes the organization's goals transparent with regard to innovation, and facilitates coordination among all the employees to achieve these goals. It promotes "mutual commitment" and motivation among employees (Adler and Chen 2011, p. 75). The below comment reveals that although regular meetings with employees are aimed at discussing KPI and targets, senior managers use them in order to provoke disputes among employees and engage them in innovation-seeking activities.

We ask employees how they see their roles in realizing a certain strategy. We meet regularly and try to discuss this issue. Then they try to translate targets into activities and tasks. [...] We have one such competitive strategy: improvement through engaging all our workers. And we use this idea in all our departments and processes. (Senior Manager 1)

A good deal of this interaction is introduced by lean management, which specifically connects diagnostic lean controls with interaction in daily and monthly lean meetings focused on improvements and innovation. Cube appears to combine traditional and lean controls (cf. Tillema and Van der Steen 2015). Lean implementation merges the countervailing elements of interactive and diagnostic systems. Adding lean meetings to the regularly held annual sessions with senior management countervails the characteristics of diagnostic controls that are traditionally deemed restricting. Still, the diagnostic system contains an element of standardization through the vari- 
ance analysis of a number of financial indicators, such as revenue or profit margin, but it is expanded by nonfinancial indicators concentrated on project improvements and innovation, such as delivery time, percentage of errors, and value added to the process. Discussions on highly standardized diagnostic lean controls such as score tables, competency matrices and process mappings help employees better understand the aims of the organizations with regard to innovation, while engaging them in the realization of the strategy, stimulating lively debate and inspiring improvements and creativity. The following quite reveals that for senior managers, lean meetings aimed at discussing diagnostic lean controls, though time-consuming and challenging, are a valuable source of local knowledge.

Visual tables" [score tables, competency matrices and process maps] are important. [...] They are reviewed daily with the team leader and managers and the leader must analyse any problems and discuss them with workers. [...] We want to make leaders concentrate on people and future processes. Such tables are time-consuming but in three teams in controlling we improved efficiency by $53 \%$, because we started to look for problems and solutions and people's development. [...] It is challenging for a leader to look for solutions and plan a few experiments with the team. (Senior Manager 3)

Thanks to lean, diagnostic controls contain a social element, introduced mainly by personal development targets for employees and competence matrices. Moreover, the social mechanism (Kennedy and Widener 2008) brought about by interactive meetings, teamwork and problem solving encourages employee decision making (Tillema and van der Steen 2015) and fosters innovative behaviour. Lean KPIs used in performance measurement and lean meetings create a system that is seen by employees as enabling and empowering, rather than restricting.

In addition to this, the interactive controls encouraged by the directors are combined with clear boundaries (the code of conduct, workshops, procedures, SLA), meaning interactive controls are focused on innovation and are more effective (cf. Simons 1995). With regular meetings, directors promote and spur innovative behaviour, but with boundary controls, they establish standards and limits within which employees are expected to perform. Managers discuss risks and opportunities during daily and monthly meetings, which stimulate engagement, but within an explicitly defined area delineated by quality controls and procedures.

We can exchange ideas, discuss a few improvements [...] (Team Manager 1) [...] This makes our [...] horizons broader, [...] but for every process [of innovation] [...] we also have various additional documents for checks, quality and control. (Process Executive 1)

Because of the described interrelationships, the boundary system, which is traditionally deemed to be restricting as it is designed to allow employees to deliver their tasks only within a predefined area (cf. Adler and Chen 2011, p. 75), is not limited only to this purpose in Cube. It also empowers employees to seek out innovative solutions for clients. As a result, employees do not perceive standardized procedures and SLAs as restrictive controls but as elements which facilitate their work (cf. Ahrens and 
Chapman 2004). One employee explained the importance of instructions in innovationseeking activities:

Instruction nicely describes the whole process, but you can also learn many things about the process from instruction. You can use it to improve the process. (Management Accountant 1)

Furthermore, the code of conduct and training on communication prepares employees to collaborate with colleagues during a meeting and challenge strategy, as well as to take a leadership role. Interestingly, one of the senior managers mentioned "standardizing the leadership" in business relations in the company. This element is essential in order to conduct successfully interactive meetings in Cube.

[During lean meetings] we tackle issues of lack of leadership. We want to standardize leadership_-if you are a leader, managing people's, colleagues' and clients' relationships must be standardized in the company. (Senior Manager 1)

There is also some evidence of a relationship between belief and boundary systems, as innovation seeking is built into the beliefs (the values in the mission statement), but carefully limited within given boundaries (the code of conduct, training, procedures, SLA) in order to reinforce effectiveness.

[In order to improve and innovate] you must clearly understand the rules that exist in the organization. (Process Manager 4)

This illustrates how the combination of two levers allows the identification or creation of a 'unique set of opportunities at a point in time given its competencies and resources' (Simons 1995, p. 16). In Cube it facilitates the search for and recognition of innovation without wasting organizational resources and taking too high a risk. All the innovative tasks must be assigned to the appropriate employees possessing the skills and competences that will enable an effective solution.

We want ad hoc tasks [within each project] to go to the right person who has the competences to solve the problems. It is a waste of time if an ad hoc task is sent to an arbitrary employee who then wastes time attempting to solve the problem or looking for someone else who can tackle the task instead. So we want to divide and group our resources by competencies, so ad hoc tasks are directed to a person with the appropriate competences. (Senior Manager 1)

The mission statement and training within the belief systems support the boundary system by setting out the key issues that are contained in the code of conduct, thus helping to delineate the acceptable domain of activity for organizational participants in line with the company's values. Materials from the training session on values received from the company as well as employee comments confirm that the initial, compulsory training of new staff clearly outlines the behaviour desired.

One of the compulsory training sessions is always on Cube's values. [...] Before a new employee starts work here, he or she must be "put in the picture" and participate in the basic training on values. (Team Manager) 
On the other hand, the SLA, code of conduct and different instructions within the boundary system aimed at establishing limits and standards also underline the importance of innovation and leadership. Therefore, they reinforce the belief system as, training on communication and the code of conduct, for example, helps employees incorporate the mission and values into ordinary activities and everyday interaction with clients and colleagues. Careful analysis of the materials received from Cube (the code of conduct and presentations from the training on communication in particular) as well as employee comments reveal the importance of team work, engagement, and innovativeness in the company's daily life.

[In Cube's code of conduct] activity within the team is also important-being engaged, suggesting new solutions, helping fellow employees. (Process Manager 4)

Finally, the belief systems and diagnostic controls are also related. Belief systems communicate the values of a company, which in turn create the framework for strategy. However, in Cube, implementation of strategy engages extensive use of diagnostic control systems that measure not only to what extent the strategy is achieved, but also, among other factors, innovativeness, improvements and value added to the processes, in order to gauge whether process innovations have helped to reach the goals.

Another target is connected with process development, [...] aimed at making us work as consultants, suggesting new technologies and new services to the client. This not only provides quality and prompt results, but also [...] makes us innovative, inventive [...] so adding value to client. (Senior Manager 1)

Diagnostic controls in Cube are designed not only to monitor and provide input on how processes work, but they also promote learning through a feedback mechanism. Moreover, the system contains various perspectives that communicate the strategy and translate it into critical success factors that can be measured. Personal development targets, client assessments, as well as lean targets are constructed in such a way as to lead employees to develop their skills and knowledge, seek new solutions and process improvements and thus satisfy the requirements of the customer. When clients assess their contact with employees, they indicate if the employees are innovative and what improvements they suggested. This element pushes employees towards innovationseeking activities in their daily contact with contractors. As a result, financial goals can also be achieved. The comment below from a senior manager suggests that this combination of belief systems and diagnostic controls creates a perpetual, repeating pattern of translating strategy into targets, then into tasks and activities necessary to innovate and improve.

And every year the process starts from the beginning: strategy, targets, translating targets into tasks and activities, discussion with workers, looking for problems, kaizen, solutions to the problems, improvements; every year it's the same. (Senior Manager 1)

Diagnostic lean controls, in particular, such as score tables, process maps and competency matrices, communicate clearly a strategy that translates strategic plans into 
targets used for standardization and control purposes. Senior managers underline that mapping of the processes especially requires a strategic approach.

We also try to create mapping of future processes. So we take the current mapping of processes, and try to simulate how it should look in the future-of course taking into consideration our strategic aims and targets. (Senior Manager 2)

Thanks to this countervailing combination with beliefs and lean enforcement, the nature of the diagnostic system works counterintuitively, as suggested by Simons (1995), reinforcing momentum for innovation with standardized procedures (Curtis and Sweeney 2017).

In summary, different combinations of levers create various types of reinforcement. A combination of only positive or negative levers creates consistent reinforcement, and thus a push for consistency in a single direction: either standardization or innovation Moreover, although some levers, by nature, provide constraints and impose control on employees, when they are combined with levers containing an element which pushes employees towards new solutions and creative thought, countervailing reinforcement occurs. This situation results in creating an innovation-friendly environment and encouraging employees to search for innovative solutions without endangering the company's goals and values. Table 1 presents a summary of all the identified combinations of control levers and their mutually reinforcing characteristics.

\section{Discussion}

Our study has highlighted how management control systems can support the coexistence of innovations and standardization. Although there are many claims made regarding management controls, there remain few empirical studies showing their impact in terms of innovation and standardization. Thus, our study provides insight into the relationship between innovation, standardization and management control in general. Analysing the relationship between different levers of control and their nature, we found that process and management innovations can coexist with standardization of those processes. This is an important finding as it overcomes the traditional view that standardization represents an organizational control that impede innovation (Birkinshaw et al. 2008; Wright et al. 2012).

We identified radical and incremental processes, as well as management innovations in the studied organization intertwined closely with standardization. We argue that the managing process and management innovations in Cube are highly standardized (Wright et al. 2012). Standardization is evident in the adoption of lean management at the system level, as its diffusion in the organization is assisted by and reliant on standardized solutions and methods of implementation, such as score tables, process maps and competence matrices (Worren et al. 1999; Wright et al. 2012). But standardization also predominates at the micro level within the organization (Courpasson 2000) due to the fact that every process improvement and innovation ends with standardization. Although this narrows the duties of Cube, the relationship between standardization and process innovation is also quite supportive, as it encourages both radical and incremental innovative effort in order to provide new services. In this way, standards 
promote local innovation and learning in the organization (David and Rothwell 1996). Indeed, it was evident in some of the employee comments that a conflictual relationship between standardization and innovation exists at the moment of refreezing the standard in order to improve processes, as well as during the mapping and standardizing of the process due to lean (see: Wright et al. 2012); however, the conflict is overcome by the simultaneous use of different control levers, such as meetings, workshops, training sessions and procedures. Furthermore, we suggest that the combination of control levers enables exploitation of existing organizational knowledge in the form of incremental management innovation aimed at improving the internal processes without crowding out more radical innovation. This is in contrast to Benner and Tushman (2003), who claim that standardization highlights only incremental innovation.

Beyond contributing to the conceptualization of innovation and standardization, the study provides insights into the relationships between different levers, as well as their impact on the coexistence of innovation and standardization. We discovered that in this organization, all the levers are tied to one another and practically each lever supports the achievement of aims by the other levers. In other words, levers of control are mutually reinforcing (Simons 1995). However, the way each lever of control interacts with the others is of particular importance in developing the unique potential of the organization studied (Henri 2006). A combination of belief and interactive controls focuses the attention of employees on innovation, while diagnostic and boundary controls are aimed at standardizing the processes. The lack of dominance of one pair over another constitutes a crucial factor (Mundy 2010), as the consistency towards innovation does not, however, crowd out standardization for efficiency and vice versa (cf. Curtis and Sweeney 2017).

Our study also reveals the countervailing combinations of levers that support the coexistence between standardization and innovation, as well as prevent the crowding out of radical innovation in favour of incremental innovations. As the positive controls (beliefs and interactive systems) are considered to contribute to more radical innovations, while negative controls (boundary and diagnostic systems) are related to incremental innovation and standardization (Simons 1995; Bedford 2015), the countervailing combination of levers minimizes such a crowding out effect. We have found specific controls, such as lean controls, service level agreement, and training, to be of specific importance for that purpose. Indeed, diagnostic lean controls such as score tables, process maps and lean KPIs are focused on the implementation of somewhat incremental management innovations, while the social mechanism brought by lean (Kennedy and Widener 2008) in the form of lean meetings and personal development of staff through competence matrices and personal development targets spurs radical process innovation. Lean meetings, in particular, combine other control levers with the interactive systems, as diagnostic lean controls, such as score tables, process maps, competency matrices and lean KPIs are discussed, providing input as to whether the constantly installed new processes are working in accordance with the ways standardized by the company (boundary systems).

The study would suggest that more countervailing combinations of controls counterbalance the nature of levers, thus moderating the contradictions between innovation and standardization. This is due to the fact that a lever that traditionally supports either standardization or innovation working in tandem with a countervailing lever changes 
its nature, reinforcing the impact of the other level and vice versa. Thus, the diagnostic control system-mainly the performance measurement system-combined with an interactive system created by various management/employee meetings is no longer restrictive and focused only on standards, but also promotes innovativeness among employees (Henri 2006). On the other hand, interactions that traditionally stimulate dialogue on new initiatives (Simons 1995) when discussing the performance measurement system during meetings, focus on the diagnostic system and standards that monitor processes. Furthermore, interactions work in Cube within the limits established by boundaries, but the SLA and procedures are not perceived by employees as restrictive; instead they are encouraged to seek innovativeness and facilitate it. Combining beliefs with boundaries ensures that innovation is built into everyday activities, albeit carefully delineated by various limits and standards. Diagnostic controls not only translate the beliefs into targets and monitor employees, but also stimulate them to find novel solutions (Simons 1995). Thus, placing a control within a specific lever is frequently too restricting in Cube, as a control can have characteristics of different levers. For instance, the SLA represents a boundary control of the nature of a diagnostic lever, and the performance measurement system is used both in diagnostic and interactive ways.

Due to the consistent and countervailing combination of levers, the management control system fosters communication among employees, managers and directors (Simons 1995; Henri 2006), improves cooperation (Mundy 2010) and develops the creative skills necessary to exploit as well as explore knowledge (Benner and Tushman 2003). At the same time, though, it steers and monitors activities, in addition to standardizing processes within the company (Simons 1995). The more levers engaged in the combinations, the stronger the reinforcement that can be achieved (see: Simons 1995).

One limitation of our research is the fact that although the case study method has the advantage of allowing an examination of the management controls, their relationship and impact on innovation and standardization in the organization, the specific context of a BPO company precludes a generalization of the results taking into account different types of companies. A further limitation of our data is that concerns a singlecompany case study based on a limited number of interviews. On the other hand, the interviews were supplemented with presentations, additional materials received from the organizations, as well as observations of the researchers who participated in the daily activities of the company for almost two years, so the qualitative material was rich and extensive, which enabled the study of the nature of levers and the relationship between different types of innovations and standardization.

\section{Conclusions}

The aim of this study was to answer the research question of how controls can support the coexistence of process and management innovations with standardization in the context of management accounting services. We collected data at a large department of a BPO company. The department is a supplier of management accounting services where the standardization needed to serve the clients is combined with constant pro- 
cess and management innovation to ensure the continuation of operations. Having collected the data, we explored the multiple relationships between levers. Set against the traditional view that standards are in conflict with innovation, we argue that both process and management innovations can coexist with standardization at the system level, as well as at the micro level within an organization (Wright et al. 2012; David and Rothwell 1996). Moreover, the different types of innovations identified in the studied organization involve significant standardization, but standards enable or even inspire innovative practices (Wright et al. 2012; David and Rothwell 1996; Damanpour 1991). This is due to the fact that standards assist lean management and its implementation in a company, providing a common language for investigation and experimentation, thus encouraging improvements based on learning from previous experience (Wright et al. 2012; Benner and Tushman 2003; David and Rothwell 1996). Standardization of processes narrows down the duties of employees and managers, thus creating a strong impetus to encourage innovation.

Our research complements the conceptualization of innovation and standardization by highlighting the role of management control systems in this relationship. The current study contributes to the growing stream of research on how management controls work collectively (Simons 1995; Otley 1999; Malmi and Brown 2008), and their impact on innovative activities (Mundy 2010; Henri 2006; Adler and Chen 2011; Widener 2007; Janka and Guenther 2018). Our primary focus is on process and management innovations (Chenhall and Moers 2015; Lopez-Valeiras et al. 2016), acknowledging both the impact on innovative activities and the need for predictability with the help of standardization (David and Rothwell 1996; Birkinshaw et al. 2008; Wright et al. 2012; Janka et al. 2019). While previous studies have provided some evidence on how countervailing but mutually reinforcing combinations of control levers affect the development of organizational capabilities, they have rarely investigated the nature of those levers and their impact on the coexistence of innovation and standardization.

The present study shows how both standardization and innovation are supported by the simultaneous use of different levers of control. We were able to do this by exploring the controls that constitute these levers. All of the identified controls enhance one another and reinforce their impact. This therefore supports Simons' (1995) statement that all levers are needed because they are mutually reinforcing (Simons 1995; Bedford 2015; Curtis and Sweeney 2017). While mutual reinforcement is consistent with the premises of the LOC framework (Simons 1995), the important finding of the present study is in showing categorically what kinds of positive and negative controls may reinforce one another, thus creating both consistent and countervailing reinforcement, in turn enabling the coexistence of innovation and standardization. The mutual reinforcement produced by two combinations of levers (belief/interactive and diagnostic/boundary) can be described as consistent, as it creates a push for consistency in the same direction (Curtis and Sweeney 2017). Although the interplay between belief and interactive levers reinforces the importance of innovation, the interactions between boundary and diagnostic systems focus on standardization. Moreover, we identified four different combinations of levers that contain countervailing forces, which thus created countervailing reinforcement (cf. Curtis and Sweeney 2017). 
We found this type of reinforcement was necessary to reduce excessive momentum towards standardization or innovation. In particular, the interplay between diagnostic and interactive levers enhanced by lean controls plays an important role in spurring controlled innovation. Nevertheless, mobilizing the other combinations of positive and negative levers (Simons 1995) prevents a crowding out effect. Such combinations of countervailing elements counterbalance the essence of levers, as "negative" levers operate in a fashion reinforcing innovation, while "positive" levers draw the management's attention to the need for control and standardization. The same controls can be used within different levers supporting both standardization and innovation and therefore the LOC framework may be too restricting in naming the controls within levers. Therefore, this study contributes to a better understanding of the relationship between levers and their nature, which is not clearly articulated in the original framework (Bedford 2015; Curtis and Sweeney 2017; Kruis et al. 2016). Furthermore, in exploring the nature of levers, we also contribute to the subject literature by showing how lean service management effectively ties the levers of control together (Kennedy and Widener 2008; Fullerton et al. 2013; Tillema and Van der Steen 2015), as it introduces a good deal of interaction with regular meetings. The description provided in the present paper provides an illustration of how traditional and lean controls may work effectively together, which differs from the findings of Tillema and Van der Steen (2015).

The study also points to broader implications of controls for adopting incremental and radical innovations. As positive controls are considered to contribute to more radical innovations, while negative controls are related to incremental innovation and standardization (Simons 1995; Bedford 2015), the simultaneous use of countervailing levers enables the exploitation of existing organizational knowledge through incremental management innovation aimed at improving internal processes without crowding out the more radical innovation necessary for the long-term survival of the organization (cf. Benner and Tushman 2003; Wright et al. 2012; Gschwantner and Hiebl 2016).

An interesting direction for future research would be to examine how a change in a control system resulting from further lean implementation influences the relationships between levers, and the impact on innovation. It would be of interest to ascertain if the changes in levers of control triggered by lean would have a positive influence on various strategic capabilities in the organization.

Acknowledgements The authors would like to thank Martin Messner and Eric Strauss, as well as participants of the 41st European Accounting Association Annual Congress in Milan (2018) for their suggestions and comments on the previous draft of this paper. We would also like to acknowledge the valuable comments and feedback from the editors of the journal and the two anonymous reviewers of the paper.

Open Access This article is distributed under the terms of the Creative Commons Attribution 4.0 International License (http://creativecommons.org/licenses/by/4.0/), which permits unrestricted use, distribution, and reproduction in any medium, provided you give appropriate credit to the original author(s) and the source, provide a link to the Creative Commons license, and indicate if changes were made. 


\section{Appendix 1}

Details of interviews/recorded and transcribed data from Cube

\begin{tabular}{|c|c|c|}
\hline Date & Interviewee(s) & Duration (mins) \\
\hline January 2016 & $\begin{array}{l}\text { Presentation by the firm: led by Senior Manager } 2 \text { with Team and } \\
\text { Process Managers, Management Accounting Specialists } 1 \text { (10 } \\
\text { people) }\end{array}$ & 153 \\
\hline January 2016 & Process Manager & 30 \\
\hline January 2016 & Process Specialist & 35 \\
\hline January 2016 & Process Manager 1 & 45 \\
\hline January 2016 & Team Manager & 57 \\
\hline January 2016 & Process Manager 2 & 38 \\
\hline January 2016 & Senior Manager 2 & 41 \\
\hline January 2016 & $\begin{array}{l}\text { Team promotion and advertising costs control and planning: Process } \\
\text { Manager } 3 \text { and Management Accounting Specialists } 1 \text { and } 2\end{array}$ & 80 \\
\hline February 2016 & Management Accounting Specialist 3 & 35 \\
\hline February 2016 & Process Executive & 65 \\
\hline February 2016 & Management Accountant 1 and Management Accountant 2 & 130 \\
\hline February 2016 & Senior Manager 3 & 48 \\
\hline February 2016 & Process Manager 4 & 41 \\
\hline February 2016 & Team Manager 1 and Process Executive 1 & 80 \\
\hline February 2016 & Process Executive 2 & 35 \\
\hline February 2016 & Senior Manager 1 & 60 \\
\hline February 2016 & Process Manager 5 & 43 \\
\hline February 2016 & Business Analyst & 45 \\
\hline February 2016 & Senior Business Analyst & 73 \\
\hline February 2017 & $\begin{array}{l}\text { Presentation by Senior Management on Lean Principles (Senior } \\
\text { Manager 1, Senior Manager 2, Senior Manager 3) }\end{array}$ & 150 \\
\hline
\end{tabular}

\section{Appendix 2}

Research instrument: themes/questions used in the interviews Personal questions:

1. What is your position?

2. When did you start working for the firm?

3. Did you get any training when you started your work, and what kind of training was it?

4. What is your educational background?

5. Do you have experience in working for any other companies, if so what was your position, and how does your work in a SSC differ from your previous experience?

6. Why did you decide to work in a SSC in the area of MA and what are your plans for future? 
7. What skills do you need for your position?

8. What do you do during a normal day (times, tasks, breaks)?

Questions for BPO general managers (senior managers)

1. What is the mission, vision and strategy of the organization?

2. What performance measurement system do you use?

3. What is the history of its development?

4. What is the current organizational structure?

5. How many clients does the organization work with?

6. Why did you decide to offer services in MA?

7. What did it take to be able to provide the services in MA (resources, skills, knowledge)?

8. What tools and methods are transferred?

9. Who makes the decisions to transfer and how are they performed, what analyses are done before, is there any risk involved, who coordinates the transfer?

10. What types of contracts are there with clients?

11. What innovations, improvements and developments are offered to clients, and are there any changes, new proposals, new processes, or new projects)?

12. How do you cooperate and communicate,- - how do you make contact, with whom, how often, and what procedures are followed?

13. How often and in what ways is cooperation evaluated?

14. What is your opinion of cooperation-what are the challenges, what would you like to improve?

15. What are your future plans?

Questions for SSC managers, executives, team and process leaders, business analysts

1. What is the structure of your team?

2. What is your responsibility and that of your team — what tools, reports do you prepare for the client, how often and how long do they take to prepare, is HR involved, what IT tools, projects, improvements, processes, innovations are involved?

3. Are there any procedures or guidelines for the preparation of work for a client, and are they similar for each client?

4. How do you communicate with clients and colleagues?

5. In what meetings do you participate?

6. Do you evaluate your workers, and if so how?

7. What challenges do you face in your work (with reference to, for example, communication with clients, data transfer, staff, deadlines, culture, stress)?

Questions for SSC specialists and management accountants:

1. What are your tasks, what tools and reports do you prepare for the client, how often and how long do they take to prepare, what IT tools are used, what improvements could be made, what tasks do you find difficult?

2. Are there any procedures or guidelines for work preparation, are they easy to follow, is it possible to ask for help?

3. How do you communicate with the client and colleagues? 
4. In what meetings do you participate?

5. How are you evaluated and how often do you get feedback and from whom??

6. What are the pros and cons of your job?

What challenges do you face in your work (with reference to, for example, communication with clients, data transfer, staff, deadlines, culture, stress)?

\section{References}

Adler, P. S., \& Chen, C. X. (2011). Combining creativity and control: Understanding individual motivation in large-scale collaborative creativity. Accounting, Organizations and Society, 36(2), 63-85.

Ahrens, T., \& Chapman, C. S. (2004). Accounting for flexibility and efficiency: A field study of management control systems in a restaurant chain. Contemporary Accounting Research, 21(2), 271-301.

Baer, M., \& Frese, M. (2003). Innovation is not enough: Climates for initiative and psychological safety. Journal of Organizational Behavior, 24, 45-68.

Bedford, D. S. (2015). Management control systems across different modes of innovation: Implications for firm performance. Management Accounting Research [Special Issue Innovation and Product Development], 28, 12-30.

Benner, M. J., \& Tushman, M. L. (2003). Exploitation, exploration, and process management: The productivity dilemma revisited. The Academy of Management Review, 28(2), 238-256.

Birkinshaw, J., Hamel, G., \& Mol, M. J. (2008). Management innovation. Academy of Management Review, $33,825-845$.

Bisbe, J., \& Malagueño, R. (2009). The choice of interactive control systems under different innovation management modes. European Accounting Review, 18(2), 371-405.

Bisbe, J., \& Malagueño, R. (2015). How control systems influence product innovation processes: Examining the role of entrepreneurial orientation. Accounting and Business Research, 45, 356-386.

Bisbe, J., \& Otley, D. (2004). The effects of the interactive use of management control systems on product innovation. Accounting, Organizations and Society, 29, 709-737.

Boer, H., \& During, W. E. (2001). Innovation, what innovation? A comparison between product, process and organizational innovation. International Journal of Technology Management, 22, 83-107.

Burns, T., \& Stalker, G. M. (1961). The management of innovation. London: Tavistock.

Chenhall, R. H., \& Moers, F. (2015). The role of innovation in the evolution of management accounting and its integration into management control. Accounting, Organizations and Society, 47, 1-13.

Choi, D. G., Lee, H., \& Sung, T. (2011). Research profiling for 'standardization and innovation'. Scientometrics, 88(1), 259-278.

Courpasson, D. (2000). Managerial strategies of domination: Power in soft bureaucracies. Organization Studies, 21(1), 141-161.

Crossan, M. M., \& Apaydin, M. (2010). A multi-dimensional framework of organizational innovation: A systematic review of the literature. Journal of Management Studies, 47(6), 1154-1191.

Curtis, E., \& Sweeney, B. (2017). Managing different types of innovation: Mutually reinforcing management control systems and the generation of dynamic tension. Accounting and Business Research, 47(3), 313-343.

Damanpour, F. (1991). Organizational innovation: A meta-analysis of effects of determinants and moderators. Academy of Management Journal, 34, 555-590.

Damanpour, F. (2014). Footnotes to research on management innovation. Organization Studies, 35(9), $1265-1285$.

Damanpour, F., \& Evan, W. M. (1984). Organizational innovation and performance: The problem of organizational lag. Administrative Science Quarterly, 29(3), 392-409.

David, P. A., \& Rothwell, G. S. (1996). Standardization, diversity and learning: Strategies for the coevolution of technology and industrial capacity. International Journal of Industrial Organization, 14(2), $181-201$.

Davila, A. (2000). An empirical study on the drivers of management control systems' design in new product development. Accounting, Organizations and Society, 25(4-5), 383-409. 
Ditillo, A. (2004). Dealing with uncertainty in knowledge-intensive firms: The role of management control systems as knowledge integration mechanisms. Accounting, Organizations and Society, 29(3/4), 401-421.

Flamholtz, E. (1996). Effective organizational control: A framework, applications, and implications. European Management Journal, 14(6), 596-611.

Fried, A. (2017). Terminological distinctions of 'control': A review of the implications for management control research in the context of innovation. Journal of Management Control, 28, 5-40.

Fullerton, R. R., Kennedy, F. A., \& Widener, S. K. (2013). Management accounting and control practices in a lean manufacturing environment. Accounting, Organizations and Society, 38(1), 50-71.

Ganter, A., \& Hecker, A. (2014). Configurational paths to organizational innovation: Qualitative comparative analyses of antecedents and contingencies. Journal of Business Research, 67(6), 1285-1292.

Grabner, I., \& Speckbacher, G. (2016). The cost of creativity: A control perspective. Accounting, Organizations and Society, 48, 31-42.

Gschwantner, S., \& Hiebl, M. R. W. (2016). Management control systems and organizational ambidexterity. Journal of Management Control, 27(4), 371-404.

Hage, J. T. (1999). Organizational innovation and organizational change. Annual Review of Sociology, 25(1), 597-622.

Helander, M., Bergqvist, R., Stetler, K. L., \& Magnusson, M. (2015). Applying lean in product development-Enabler or inhibitor of creativity? International Journal of Technology Management, 68(1/2), 49-69.

Henri, J. (2006). Management control systems and strategy: A resource-based perspective. Accounting, Organizations and Society, 31, 529-558.

Janka, M., \& Guenther, T. W. (2018). Management control of new product development and perceived environmental uncertainty: Exploring heterogeneity using a finite mixture approach. Journal of Management Accounting Research, 30(2), 131-161.

Janka, M., Heinicke, X., \& Guenther, T. (2019). Beyond the "good" and "evil" of stability values in organizational culture for managerial innovation: The crucial role of management controls. Review of Managerial Science. https://doi.org/10.1007/s11846-019-00338-3. (in print).

Järvenpää, M. (2007). Making business partners: A case study on how management accounting culture was changed. European Accounting Review, 16(1), 99-142.

Jørgensen, B., \& Messner, M. (2009a). Management control in new product development: The dynamics of managing flexibility and efficiency. Journal of Management Accounting Research, 21(1), 99-124.

Jørgensen, B., \& Messner, M. (2009b). Accounting and strategising: A case study from new product development. Accounting, Organizations and Society, 35(2), 184-204.

Kennedy, F. A., \& Widener, S. K. (2008). A control framework: Insights from evidence on lean accounting. Management Accounting Research, 19, 301-323.

Kimberly, J. R. (1981). Managerial innovation. In P. C. Nystrom \& W. H. Starbuck (Eds.), Handbook of organizational design (pp. 84-104). New York, NY: Oxford University Press.

Kirner, E., Armbruster, H., Kinkel, S., \& Som, O. (2011). Continuous improvement processes in manufacturing enterprises as an enabler of process innovation. International Journal of Manufacturing Technology and Management, 22(3), 207-218.

Kruis, A. M., Speklé, R. F., \& Widener, S. W. (2016). The levers of control framework: An exploratory analysis of balance. Management Accounting Research, 32, 27-44.

Laursen, K., \& Salter, A. (2006). Open for innovation: The role of openness in explaining innovation performance among U.K. manufacturing firms. Strategic Management Journal, 27(2), 131-150.

Levin, R. C., Klevorick, A. K., Nelson, R. R., \& Winter, S. G. (1987). Appropriating the returns from industrial R\&D. Brookings Papers on Economic Activity, 18(3), 783-831.

Lewis, M. W. (2000). Exploring paradox: Toward a more comprehensive guide. Academy of Management Review, 25(4), 760-776.

Linder, S., \& Torp, S. S. (2017). Middle managers' engagement in autonomous strategic actions: Does it really matter how top managers use budgets? IEEE Transactions on Engineering Management, 64(4), 450-463.

Lippman, S. A., \& Rumelt, R. P. (1982). Uncertain imitability: An analysis of interfirm differences in efficiency under competition. Bell Journal of Economics, 13, 418-438.

Lopez-Valeiras, E., Gonzalez-Sanchez, M. B., \& Gomez-Conde, J. (2016). The effects of the interactive use of management control systems on process and organizational innovation. Review of Managerial Science, 10, 487-510. 
Lövstål, E., \& Jontoft, A. M. (2017). Tensions at the intersection of management control and innovation: A literature review. Journal of Management Control, 28, 41-79.

Lukas, B., \& Ferrell, O. C. (2000). The effect of market orientation on product innovation. Journal of the Academy of Marketing Science, 28(2), 239-247.

Malmi, T., \& Brown, D. A. (2008). Management control systems as a package-Opportunities, challenges and research directions. Management Accounting Research, 19(4), 287-300.

Merchant, K., \& Van der Stede, W. A. (2007). Management control systems (2nd ed.). Harlow, Essex: Prentice Hall, Pearson Education Limited.

Mol, J. (2015). Editorial: Special issue on innovation and product development. Management Accounting Research, 28, 2-11.

Mol, M. J., \& Birkinshaw, J. (2009). The sources of management innovation: When firms introduce new management practices. Journal of Business Research, 62, 1269-1280.

Mundy, J. (2010). Creating dynamic tensions through a balanced use of management. Accounting, Organizations and Society, 35(5), 499-523.

Otley, D. T. (1999). Performance management: A framework for management control systems research. Management Accounting Research, 10, 363-382.

Ouchi, W. (1979). A conceptual framework for the design of organizational control mechanisms. Management Science, 25(9), 833-848.

Pesämaa, O. (2017). Personnel- and action control in gazelle companies in Sweden. Journal of Management Control, 28, 107-132.

Reichstein, T., \& Salter, A. (2006). Investigating the sources of process innovation among UK manufacturing firms. Industrial and Corporate Change, 15(4), 653-682.

Rogers, E. M. (2003). Diffusion of innovations (5th ed.). New York: Free Press.

Rosner, M. M. (1968). Economic determinants of organizational innovation. Administrative Science Quarterly, 12, 614-625.

Simons, R. (1987). Accounting control systems and business strategy: An empirical analysis. Accounting, Organizations and Society, 15(1-2), 127-143.

Simons, R. (1995). Levers of control. Boston: Harvard University Press.

Simons, R. (2000). Performance measurement and control systems. Upper Saddle River, NJ: Prentice Hall.

Smeds, R. (1994). Managing change towards lean enterprises. International Journal of Operations \& Production Management, 14(3), 66-82.

Speklé, R. F. (2001). Explaining management control structure variety: A transaction cost economics perspective. Accounting, Organizations and Society, 26, 419-441.

Speklé, R. F., Van Elten, H. J., \& Widener, S. K. (2017). Creativity and control: A paradox evidence from the Levers of Control Framework. Behavioral Research in Accounting, 29(2), 73-96.

Stata, R. (1989). Organizational learning-The key to management innovation. Sloan Management Review, 30(Spring), 63-74.

Strauss, E. R., \& Zecher, Ch. (2013). Management control systems: A review. Journal of Management Control, 23, 233-268.

Thompson, V. A. (1965). Bureaucracy and innovation. Administrative Science Quarterly, 10(1), 1-20.

Tillema, S., \& Van der Steen, M. (2015). Co-existing concepts of management control: The containment of tensions due to the implementation of lean production. Management Accounting Research, 27, 67-83.

Tornatzky, L. G., \& Fleischer, M. (1990). The processes of technological innovation. Lexington, MA: Lexington Books.

Utterback, J. M., \& Abernathy, W. J. (1975). A dynamic model of product and process innovation. Omega, 3(6), 639-656.

Van De Ven, A. H. (1986). Central problems in the management of innovation. Management Science, 32(5), 590-607.

Widener, S. K. (2007). An empirical analysis of the levers of control framework. Accounting, Organizations and Society, 32(7-8), 757-788.

Womack, J., Jones, D., \& Roos, D. (1990). The Machine That Changed the World. New York, NY: Rawson Associates.

Worren, N. A. M., Ruddle, K., \& Moore, K. (1999). From organizational development to change management: The emergence of a new profession. Journal of Applied Behavioral Science, 35(3), 273-286.

Wouters, M., \& Wilderom, C. (2008). Developing performance-measurement systems as enabling formalization: A longitudinal field study of a logistics department. Accounting, Organizations and Society, 33, 488-516. 
Wright, C., Sturdy, A., \& Wylie, N. (2012). Management innovation through standardization: Consultants as standardizers of organizational practice. Research Policy, 41(3), 652-662.

Wu, L. Y. (2010). Which companies should implement management innovation? A commentary essay. Journal of Business Research, 63(3), 321-323.

Zaltman, G., Duncan, R., \& Holbek, J. (1973). Innovations and organizations. New York: Wiley.

Publisher's Note Springer Nature remains neutral with regard to jurisdictional claims in published maps and institutional affiliations. 